Can parental responses to adult children with schizophrenia be conceptualised in terms of loss and grief? A case study analysis

\author{
JAMES OSBORNE \& ADRIAN COYLE \\ Department of Psychology, University of Surrey, UK
}

Correspondence to: Dr James Osborne, Counselling Psychologist, St John’s CMHC, St John’s Road, Sevenoaks, Kent TN13 3LR, UK.

The full reference for the published version of this paper is:

Osborne, J., \& Coyle, A. (2002). Can parental responses to adult children with schizophrenia be conceptualized in terms of loss and grief? A case study analysis.

Counselling Psychology Quarterly, 15(4), 307-323. 


\section{Can parental responses to adult children with schizophrenia be conceptualised in terms of loss and grief? A case study analysis}

\section{Abstract}

It has been suggested that parental responses to adult children with schizophrenia may involve feelings of loss and grief, centred around loss of the pre-morbid version of their child. In this exploratory study, an in-depth case study analysis of four parental accounts of their responses was undertaken in order to obtain insights into whether these responses can be conceptualised in terms of loss and grief, with the aim of informing therapeutic practice with parents in this position. Information was also obtained on how parents coped with the reactions that their child's condition elicited in them. Data were analysed using Interpretative Phenomenological Analysis. In relation to the central research question, it was found that the perception of loss was not uniform amongst participants. Three acknowledged a sense of loss at least to some extent but one parent resisted such an interpretation because she perceived a continuity over time in her son's behaviour and she also challenged her son's diagnosis. One parent acknowledged a loss of his daughter's premorbid self but qualified this by pointing to her continued physical presence. The usefulness of existing models of grief are examined in light of the findings. The implications for the practice of counselling psychology are discussed. 


\section{Can parental responses to adult children with schizophrenia be conceptualised in terms of loss and grief? A case study analysis}

\section{Introduction}

It is acknowledged that families face a formidable burden in caring for a relative with serious mental illness (Cook et al., 1994; Hatfield, 1978; Hoenig \& Hamilton, 1966; Horwitz \& Reinhard, 1995; Pariante \& Carpiniello, 1996; Thompson \& Doll, 1982). Caring for a son or daughter with a mental illness involves unique financial, social and emotional burdens (Crotty \& Krulys, 1986; Doll, 1976; Gubman \& Tessler, 1987; Hatfield, 1987; Maurin \& Boyd, 1990; Potasznik \& Nelson, 1984). These are due mainly to the specific changes in behaviour that parents experience in their son or daughter which include withdrawal, psychotic symptoms, behavioural excesses and impaired social performance (Birchwood \& Smith, 1987).

It has been suggested that part of the burden for parents of (adult) children with schizophrenia involves dealing with feelings of loss and grief (Atkinson, 1994; Chafetz \& Barnes, 1989; Davis \& Schultz, 1998; MacGregor, 1994; McElroy, 1987; Miller, 1996; Parker, 1993; Ryan, 1993; Solomon \& Draine, 1996). This suggestion arises from the belief that, with the onset of schizophrenic symptoms, parents experience a perceived loss of the pre-morbid version of their child, a loss of their child's potential (Davis \& Schultz, 1998; Ryan, 1993) and therefore the loss of hopes and aspirations for their child's future (Miller, 1996; Parker, 1993). Conceptualising these experiences as a loss - termed by Miller (1996) a 'psychic loss' - may not be straightforward, however, due to the insidious 
and cyclical nature of the illness and periodic reappearances of the child's 'former self'. Detailed parental accounts of their responses to a son or daughter with schizophrenia are therefore required to explore the validity of this conceptualisation.

If parental responses can be conceptualised in terms of loss, there may be some overlap between parental experiences and the experience of grief following a bereavement, although the continued physical presence of the son or daughter means that one experiential domain does not map exactly onto the other (Solomon \& Draine, 1996). An understanding of the grieving process, prompted by Freud's (1917) seminal paper Mourning and Melancholia, led western psychotherapeutic approaches to claim that 'grief work' is essential for the resolution of grief (Davy, 1998). The work of many authors, spanning much of the twentieth century, sought to develop this 'grand theory', including Bowlby (1969, 1973, 1980), Lindemann (1944, 1979), Parkes (1965, 1980, 1985, 1993, 1998) and Worden (1991, 1996). Therapeutic approaches are said to facilitate grief work by concentrating on making the loss 'real', to enable detachment from the deceased and engagement in new relationships (see Raphael \& Nunn, 1988).

Throughout the 1990s, however, Margaret Stroebe and colleagues have undertaken literature reviews and empirical studies which call into question the grief work hypothesis (e.g., Schut et al., 1997; Stroebe, 1992, 1994, 1998; Stroebe et al., 1994). She suggests that there is insufficient empirical evidence to confirm the claims of theorists who subscribe to this idea. From this body of research, she developed a new model of coping with loss called the 'Dual Process Model' (Stroebe, 1998). In essence, this suggests that the avoidance of grief work - which she termed 'restoration-orientation' - can be useful if oscillation occurs between this and the 'real' work or working through of grief - which she 
termed 'loss-orientation'. This model, however, may prove problematic if used in cases where experiences of loss are complex. Miller (1996) acknowledged the usefulness of stage models in facilitating complex grief work when he took Worden's (1991) four-task model of grief and adapted the last two tasks to develop a model specifically to address the sense of loss to mental illness. These tasks were transformed into 'accommodations to the loss via relationships outside that with the mentally ill relative' and 'accommodations to the loss via the relationship with the mentally ill relative’ (p. 633). Although researchers have empirically explored loss and grief among parents of people with schizophrenia (Atkinson, 1994; Davis \& Schultz, 1998; Miller et al., 1990; Solomon \& Draine, 1996), not only has little attention been paid to the actual conceptualisation of loss but also no qualitative work has been undertaken specifically in the area of 'psychic loss'.

The aim of the present study was to explore parental responses to having a child diagnosed with schizophrenia, with the research being informed by existing models of grief. In this study, we use the term 'child' and 'children' to refer to offspring, regardless of their age, although we are aware of the danger of such terms infantilising those to whom they refer. The study involved elaborating parents' understanding of and responses to their children's schizophrenia and exploring whether these responses could reasonably be interpreted and understood in terms of loss and grief. The intention was to use the research findings to identify therapeutic interventions which could help parents resolve problematic feelings about their children with schizophrenia.

\section{Method}




\section{Participants}

Parents of people who had been diagnosed with schizophrenia were recruited through the National Schizophrenia Fellowship (NSF), an organisation which aims to help people with serious mental illness, their families and carers. Local group co-ordinators in one geographical area (Surrey) were provided with information about the study and were asked to invite members to take part. Four parents agreed to participate.

\section{Interview Schedule}

Data were collected through interviews, using a semi-structured interview schedule to elicit information relating to parents' responses to their son or daughter's condition and whether they experienced their son or daughter's condition in terms of loss. Questions were carefully designed to avoid leading participants into simply complying with this construction of their experiences. For example, the possibility that parents might construct their child's condition in various ways was presented and then parents were invited to reflect upon how they thought of their child's condition and of the life changes associated with it. Participants were asked to provide a history of their child's condition, including their emotional and practical reactions to this, how they coped with any negative feelings and what support (if any) they received from others.

\section{Procedure}

Two participants were interviewed in their homes and two were interviewed at the researchers' university base. Interviews were conducted by the first author and lasted 5580 minutes. Before the interviews, all participants signed a consent form and completed a demographic information questionnaire. Due to the sensitive nature of the research topic and the potential for the interview to cause distress for participants, interviews were 
undertaken using a basic counselling-style format, following the recommendations of Coyle (1998). On completion of the interview, each participant was offered a follow-up counselling session to talk through any feelings of distress. No participant availed of this offer. Interviews were audiotaped and transcribed verbatim.

\section{Analytic Strategy}

An idiographic approach was adopted in the analysis of the interview data, analysing each case individually in order to produce detailed accounts of parental responses. Although there has been a tradition of using clinical case studies in psychology, a decline in their use in research occurred in the middle part of the twentieth century (Runyan, 1982). A revival of interest, however, can be observed more recently in the work of writers and researchers such as Jones (1993), Josselson and Lieblich (1993), McAdams (1988) and Smith (1990, 1991) and colleagues (Smith et al., 1995).

The data were analysed using Interpretative Phenomenological Analysis (IPA) (Smith, 1996; Smith et al., 1997, 1999). This method of analysis is concerned with developing an 'insider’s perspective' (Conrad, 1987) on participants' experiences and concentrates on the meanings that they attach to their experiences. It requires the detailed analysis of accounts of experiences offered by small samples, with the aim being to say something meaningful about the cognitions and emotions which are reflected in these accounts.

The analysis involved examining the transcript of each interview in detail. During repeated readings of each transcript, notes were made of significant or interesting points related to the research topic. These notes formed the basis for emergent themes which encapsulated the essence of significant points within the participant's account. These relatively fine- 
grained themes were then amalgamated where possible into more analytic 'superordinate themes'. However, steps were taken to ensure that these themes remained grounded in the participant's account by checking for evidence in the transcript which would support the themes. Although each transcript was analysed on an individual basis, inevitably the analysis of previous cases influenced the analysis of subsequent ones to some degree.

IPA recognises that the research product necessarily represents the outcome of a dynamic interaction between participants' accounts and the researchers' interpretative frameworks (Smith et al., 1999). It is therefore necessary to reflect upon the researchers' interpretative frameworks in relation to this topic and the ways in which these frameworks may have influenced the analysis. The interpretations of the first author (who conducted the fieldwork and the bulk of the analysis) will have been shaped primarily by his position as a counselling psychologist in training and by his work with people with schizophrenia and their carers in clinical practice. The second author (who helped guide the research design, directed the analysis and checked interpretations) is a social psychologist who has conducted research in the field of bereavement which helped to inform his contribution. It could be argued that the analysis of participants' accounts within such interpretative frameworks - far from resulting in a research product tainted by the researchers' subjectivity - produced an analysis that made constructive use of informed subjectivities. All interpretations offered by the first author were checked by the second author in the hope that this would enable unwarranted, idiosyncratic interpretations to be identified and removed. In addition, all major interpretations are illustrated by quotations from the interviews, thereby demonstrating the basis for these interpretations and enabling readers to assess their persuasiveness for themselves. 
In the quotations presented in the analysis, information within square brackets has been added for clarification and ellipsis points (...) indicate where words or a passage have been omitted from the original quotations. All identifying information, such as names and locations, have been changed to pseudonyms to protect the confidentiality of the participants.

Note that on occasions, participants talked not only about their experiences but also about the experiences of other family members. Although the accuracy of this data is open to question because of its second-hand nature, it will sometimes be included in the analysis as it provides some indication of the extent to which the family system can be challenged by accommodating a person with schizophrenia. However, readers should treat this data with caution.

\section{Analysis}

Case Study One: Jean

Jean is 54 years old and is married to the father of her three children. They live with their son, Timothy (22) who was diagnosed with schizophrenia one year ago. He has displayed symptoms of schizophrenia for four years during which time Jean has been his main carer. Her younger daughter is at university and her other daughter is married.

\section{$\underline{\text { Uncertainty prior to diagnosis }}$}

Jean described a long period of time between first observing her son's difficult behaviour and his diagnosis of schizophrenia. This was described as a period of three years of not knowing what the cause of his behaviour was. She explained that an earlier diagnosis 
would have provided her with a better understanding of his behaviour and also how to react to his criticisms. When incidents occurred with her son, she 'put it down to the behaviour from this incident [a fight Timothy was involved in] more than thinking "This is a mental illness.” I can honestly say it wasn’t until the breakdown and he was put into hospital that we ever thought he was mentally ill.' It would seem that Jean had initially interpreted this unusual behaviour as a manifestation of temporary destabilisation instead of the first sign of mental illness (Terkelsen, 1987). Later in the interview, she explained that in retrospect she began to 'pull the wool over my eyes' to guard herself from admitting it was mental illness. She went on to explain that 'you are confronted with a situation in which you just think the person involved has just totally gone against the family...the total trauma for parents.'.

\section{$\underline{\text { Interpreting the illness in terms of loss }}$}

In the early stages of the illness, Jean said that she perceived a change in her son. She described him as a 'very different son and a son, oddly enough, who had been so laid back and such an easy going personality.' It would seem from this that Jean felt that her son's former self had receded. She confirmed this later in the interview when, unprompted, she explained that having a son with schizophrenia was like a 'bereavement because one felt one had lost the person one knew...almost like a living death.' Note here the use of the general term 'one' instead of the more personal 'I': this could be interpreted as a rhetorical distancing of herself from a situation which would be too painful to talk about in personal terms. Such a loss has been conceptualised in the literature on carers of people with mental illness as a 'psychic loss' (Miller, 1996), in which the person lives on but the relationship changes profoundly. This was illustrated when Jean explained that 'his symptoms started to get worse, his relations with us broke down completely.' For Jean, her loss involved the 
loss of aspirations for her son, including his academic potential and his future happiness. She reported that 'he did actually have a good brain so it was a little frustrating to see him, as we perceived it, as losing all his talents.' It is possible that the family therapy which Jean and her family were attending at the time of the interview led to her conceptualising her experiences in terms of loss. She suggested that 'this [the conceptualisation of her experiences in terms of bereavement] did come out very much’ in therapy.

Although in one of her comments (cited earlier) Jean implied that she felt her son's former self had been 'lost', elsewhere she described this former self as 'trapped' because on occasions he would 'laugh and carry on just like he used to'. Jean went on to explain that 'it's like a blinding glimpse of life...you think [sigh] "That's the person we used to know and love."' McElroy (1987) claimed that this periodic reappearance of the 'former self' serves to prolong periods of bereavement. It would seem, however, that Jean conceptualises these glimpses as a sign of hope for the return of her son's pre-morbid self: 'there is a good, possibly sixty per cent of the person does return... what is different is the lifestyle you lead.' This perhaps indicates that although she feels that she has lost the premorbid version of her son, she still has expectations that the majority of his former self will return and therefore perhaps in one sense the loss is 'unreal' or temporary to her.

\section{$\underline{\text { Emotional reactions }}$}

During the initial stages of her son's illness, prior to his diagnosis, Jean recalled feeling 'extremely distressed' due to her son's verbal abuse towards her. She has since found that this abuse was a reaction to voices that he was hearing. She also alluded to her frustration over Timothy's stubbornness, suggesting that he would not see 'anybody else's point of view' and also his alienation from the family: 'he came down to eat, he was totally silent, 
shoved his plate to one side and you couldn’t communicate with him.' It has been suggested that such behaviour directed at carers may be very difficult to cope with (Gibbons et al., 1984; MacCarthy, 1988).

Following her son's diagnosis, Jean reported that her initial emotion was one of shock, describing it as 'a bit earth shattering'. She also described a feeling of 'flatness'. These emotions were said to have given way to feelings of guilt, which seemed to lead to selfblame. Jean explained that these 'enormous feelings of guilt' were due to looking back and thinking 'if I hadn’t had done that [argued], perhaps he wouldn’t have got so stressed.' She reported that Timothy's father also felt guilty about how he had dealt with his son. It would appear that this guilt may have led them to blame each other: 'it's human nature you accuse the other person - "If you hadn't have been so strict this wouldn't have happened”..."If you hadn’t been so lenient that would have happened.”' Jean went on to express the view that the friction that this caused 'can pull relationships apart.' It has been suggested in the bereavement literature that similar emotions of guilt are experienced by parents who have developmentally disabled children and experience grief reactions (Olshansky, 1962). The expression of these emotions, Worden (1991) suggests, are a vital part of the second task in his reminiscence phase, that of expressing overt and latent affect. Such experiences of loss can have serious adverse consequences amongst couples (Cook \& Oltjenbruns, 1989; Kohner \& Henley, 1992; Long, 1992; Schatz, 1986).

\section{$\underline{\text { Coping with the loss }}$}

Jean reported that each family member dealt with Timothy's changing behaviour in different ways. Her husband was said to have 'distanced himself psychologically’ and concentrated his thoughts on work, a response often associated with fathers coping with 
loss (Doka \& Martin, 1998; Forrest, 1983; Littlewood et al., 1991). Jean explained that other family members also distanced themselves. She made this easier for them by limiting her communication with them about Timothy. This represents a standard strategy for protecting others from an unpleasant event (Rando, 1986). Further evidence of this came when Jean explained that she has 'never actually told my mother...as she’s 80 next year...I feel fundamentally she wouldn't cope.' She concluded by remarking that it is 'interesting how you sort of protect your own circle.' It has been suggested that this may engender an inability to grieve appropriately for both the protector and protected (Mander, 1994). Jean said that she gained support from her church, as a place 'one could go and be quiet', and she found her son's community psychiatric nurse 'extremely helpful', as she was able to 'get a bit of a relationship going' with him. She also expressed her distress to her younger daughter who was said to have 'just been absolutely incredible. I suppose with her training [psychology graduate] she was the best person. She was better than my husband...she must have been broken hearted herself.' This quotation illustrates how important Jean found it to discuss her son with a close family member.

\section{Adjusting to the loss}

In her adjustment to the loss of 'the person one knew', Jean talked about having 'your own life as well...I mean our life has become totally altered due to the situation, which one does willingly because he’s our son and we love him dearly, but there's got to be an element of us attaining our lives as well.' From this quotation it would seem that she has tried to continue to live her own life with her husband, yet despite this attempt, Jean finds it difficult as illustrated in the following remark: 'He'll often be there in the evening on his own...that is heartbreaking and it's even worse if we go out...you feel really guilty for going out, thinking "Well why should we be going out for the evening enjoying 
ourselves?"' This may reflect Jean's difficulty in adjusting to the new post-diagnosis version of her son.

\section{Case Study Two: Amy}

Amy is 66 years old, currently lives on her own and became a widow following her husband's suicide ten years ago. She has a daughter and two sons. Her eldest son, Ian (34) was diagnosed with schizophrenia 16 years ago after graduating from Cambridge University. Up until three years ago, he lived at home. He currently lives locally in supported housing and Amy sees him once a fortnight. During the interview, Amy appeared reluctant to talk about her emotional responses to her son's condition and tended to change the subject when the topic of emotional responses was raised.

\section{$\underline{\text { Resisting the diagnosis }}$}

Although it would seem that Amy accepts that her son has an illness, she reported that she does not accept her son's diagnosis of schizophrenia, explaining that 'it's hard to accept, erm, even now I can’t accept it fully.' She went on to suggest that she thinks it 'may be something like Asperger's syndrome...I've read a lot of books about it... and the symptoms of that seem to fit his case exactly. He's not a split personality at all. I know he's had confused thoughts but all the other symptoms are to do with Asperger's syndrome.' Here she seems to justify her questioning of the diagnosis of schizophrenia firstly by invoking the popular representation of schizophrenia as 'split personality' and distancing her son from this and secondly by constructing his symptoms as only partly overlapping with those of schizophrenia. It would seem that another reason why she does not interpret her son's behaviour in terms of schizophrenia and asks the question 'Is it possible they [the psychiatrists] have made the wrong diagnosis?' is because 'he manipulates the doctors and 
psychiatrists.' This was illustrated later when she explained that 'knowing how manipulative he is and clever, I think he's quite capable of putting on the symptoms - not to start with because I think it was a nervous breakdown.' Note the application of the nonspecific label 'nervous breakdown' to his condition. This resistance to the diagnosis of schizophrenia and the search for alternative interpretations of his behaviour and condition are also reflected in the following quotation where Amy explained that her son 'used to get hallucinations - this was when he was very ill - over his food like a plate of food....and he had very, very bright lights, but I think it was [due to being] over-worked.’

\section{Continuity of the person}

Amy suggested that her son was not a different person because of his condition, remarking that 'he’s always been different and he’s always caused problems in the fact of tensions and every time we went on holiday as a family...it was ruined.' This may suggest that Amy did not perceive her son's current self as significantly different from how he was throughout his childhood and therefore no loss of a pre-morbid self was believed to have occurred. Instead, in her account, there appeared to be some continuity in how she represented him. This was further illustrated when Amy explained that 'I don't think he's changed... he's always been like that... a bit difficult, erm, I feel he’s the same person.'

\section{Coping with the condition}

When asked how she coped with her son's illness, Amy explained that 'I think I haven't coped too badly... somehow you get the inner resources to cope with things.' This suggests that she believes she has gained an inner strength to cope without help from others. This was further illustrated when she reported that 'I don't like to distress them [her other children]...because my daughter has got her own little children to bring up and 
Jonathan [other son] has got a nice girlfriend. I feel it's my, I've got to deal with it - in a way it's my problem. I'm the mother.' It appears that Amy has isolated herself from the rest of her family in terms of coping with her son, as she perceives it to be her problem. As well as indicating the standard positioning of mothers as being primarily responsible for the care of their children, this could also be seen as reflecting some degree of self-blame, a reaction perhaps evoked by the routine blaming of mothers for the occurrence of any problems with their children (Caplan, 1985).

\section{Aspirations for the future}

Amy explained that she felt unsupported by her son's social worker as illustrated by the following quotation: 'Well if I could talk to somebody who'd listen you know, like the social worker - she doesn't really listen.' She went on to explain that she wanted them to 'support me in the move that I think, and my son thinks, that he is well enough to get some paid, interesting work, give it a go but they won't. They either say it's too early - they have been saying that now for years. I mean it’s 12 years since he left Cambridge... he can’t be a solicitor without this year course [one year law course].' It would seem from these quotations that the support Amy feels she needs is help in getting her son to fulfil his premorbid potential. This could be interpreted in one sense as Amy seeing her son's possible stage of remission as a full recovery from his illness and seeing the social worker as repressing her future part-images of her son (Terkelsen, 1987). It may also show how Amy continues to invest her hopes in her son's earlier life script instead of considering that these investments may be lost and that hopes may need to be reconceptualised. It is suggested that this a common feature of loss among parents within Western cultures (Braun \& Berg, 1994) and can be seen as impeding the overall acknowledgement of loss, which is the first stage of Worden's (1991) model. 


\section{Case Study Three: Graham}

Graham is 76 years old and lives with his 40-year-old daughter, Rachel. She has been displaying symptoms of schizophrenia for 20 years and was diagnosed with schizophrenia five years ago. Graham has cared for Rachel since the onset of these symptoms as well as caring for his late wife who also had schizophrenia.

\section{Qualified interpretation of the illness in terms of loss}

At first, Graham explained that he did not perceive the illness-related changes in his daughter as a 'loss': 'No I don’t see it as losing a daughter really... no I don’t feel I've lost her.' Further evidence of this came later in the interview when he stated with insistence that 'If she was suddenly taken ill [or] she was taken away I might feel I've lost a daughter of course but no, not at the moment, no, no, no.’ It would seem, however, that although here Graham states that he does not conceptualise his response to his daughter's condition in terms of loss, the following quotation could be interpreted as acknowledging a 'psychic loss' (Miller, 1996): 'She’s only physically the same...you know, yes, she’s a daughter alright, she's in a bad mental state but so, I mean I've lost a daughter in the sense that she's not really intelligent and doesn't say, doesn't converse really at all, so in that respect I lost a daughter but she's there in presence.' In this extract, Graham points to the physical continuity in his daughter over time but contrasts this with the psychological and social discontinuity that has been occasioned by her condition. Remarks later in the interview once again suggested that he experienced some sense of loss when he reminisced about how his daughter used to be, saying that as 'a young child she was delightful and very beautiful and [I was] very proud of her of course, so it is very sad that she has gone this way.' Although Graham felt he had lost the daughter he used to know, there seemed to be 
little expression of sadness but rather acceptance and a feeling of lacking control over the situation as illustrated in the following quotation: 'But there is nothing I can do about it. One has to accept these things. Well, you know, depressing as they are... one must accept. If you don't you could make yourself ill.' This could be interpreted as a successful resolution of grief or as a conscious or unconscious attempt to ignore potentially threatening thoughts or feelings - something that is defined as an extreme coping mechanism for loss, termed ‘escape’ (Bowlby, 1980; Glick et al., 1974; Lindemann, 1944; Parkes, 1998).

\section{Coping with the illness}

It would appear that Graham’s main method of coping with his daughter's illness revolved around distancing himself from it both mentally and physically. This was illustrated when he explained that 'for most of the time I've been out at work. I mean, I worked till I was 70 and then I took on a part time job...I mean, to a certain extent out of sight and out of mind. You see, I was able to dismiss it and concentrate on my work...I coped with it that way otherwise if I'd had to live with it all these years...if I'd had to full time, you know, at home - well, I don't know. I'd be in a terrible state.' This type of coping has been referred to as 'masculine grief' as such distancing from emotionally threatening situations has been found to be a standard male response (Martin \& Doka, 1996). Graham went on to suggest that 'It's only this last year, as I say, that I've given up work that it's pressurised me more shall we say and concerned me more.' This quotation suggests that Graham has more recently found coping with his daughter and her illness to be more difficult due to spending more time with her. This could been seen as a time when Graham can no longer avoid confronting his thoughts and feelings about his daughter. 


\section{$\underline{\text { Support }}$}

Graham rarely spoke of seeking support for himself apart from one point in the interview when he reported attending the NSF carers support group. He explained that 'I thought it might be helpful so, yes, I - well, I don’t think I get a lot from it...It was interesting to know that someone had a relative that was - well, had similar problems to my daughter. I don't know that she [the other carer] said he [her son] had any destructive habits so from that point of view I felt she was a little better off.' These comments could be interpreted as suggesting that the most credible support for Graham would have been offered by someone who was in a situation that was closely analogous to his own. Graham may see their experiences as enabling them to truly understand and empathise with his situation. On the other hand, his account could be interpreted as indicating a reluctance to be supported.

\section{Case Study Four: Linda}

Linda is 69 years old and is widowed following the death of her husband 15 years ago. She lives with her 29-year-old son, Liam, who was diagnosed with schizophrenia four years ago. He has displayed symptoms of schizophrenia for 15 years and has been cared for by Linda throughout his life.

\section{Interpreting the illness in terms of change and loss}

Linda reported feeling that she had lost her son through his illness, explaining it is 'like something in another world. You know, you think you're in another world because you can't believe what's happening to you because one minute you love them and then you think it's the devil himself got them.' This perhaps suggests that Linda interprets her son's illness in terms of it having occasioned a sudden and difficult-to-believe transformation in her son's self. Later in the interview, however, she points to a continuity at some level, 
although at the same time implies change, saying 'as a kid, he’s always been hard work for us - well, it wasn't same thing as what his schizophrenia is but he's always had them [behavioural problems]. There's no getting away from that - he's had that from when he was a baby, you know. When it's schizophrenia it's a totally different thing altogether.' Here continuity is highlighted in her son's behavioural problems but these are differentiated from schizophrenia.

\section{$\underline{\text { Emotional reactions }}$}

There were few occasions during the interview when Linda expressed any emotions about the changes in her son and the 'loss' of her son to schizophrenia. On one occasion she explained that it is 'very sad, very sad' to think of how her son used to be compared to how he is now. Later in the interview, whilst reminiscing, Linda stated that she felt 'very hurt about it, not knowing what it was and I feel that I - I don't feel that I'm to blame for it like that [social worker] said I was. How can I be blamed for giving one of my children schizophrenia?'. This suggests that she is upset about her son's illness yet it is difficult to determine whether these emotions were compounded by Linda's interpretation of her interactions with the social worker, when she seemed to feel that she was being held responsible for her son's condition. To the extent that Linda's recollection of her interaction with the social worker is accurate, this may again be seen as highlighting the way in which mothers tend to be routinely blamed for causing dysfunction in their children (Caplan, 1985) (see Jean’s case for an earlier example).

\section{Coping with negative feelings}

Linda reported that she deals with her sadness by going 'for a walk, go out in the garden and lose yourself. You know no one else will listen to you.' This seems to denote a reliance on oneself rather than on others perhaps because of experiences of not being 
heard. She also explained that 'I think you hide them [feelings] a lot. I think you keep them in, to yourself, which makes it worse...I mean you can admit to your family but you don't want to go out to the world because people have got a different view about it [schizophrenia].' Here, Linda seems to be referring to having suppressed her emotions or having shared them only with a limited audience because of an awareness of the stigma attached to schizophrenia. Miller (1996) suggests that alongside the abstract nature of 'psychic loss', the stigma of the illness serves to inhibit open discussion of the loss and thus causes protracted grief. Linda concluded by remarking that 'You try to hide it all, you know. You think it'll go away but it's never going to go away.' It would seem from this that Linda internalises her emotions in the hope that her painful feelings will disappear, yet she acknowledges that this is not going to happen.

\section{Discussion}

\section{Limitations of the study}

The self-selected sample for this study included those parents who were involved in carers' groups of the NSF. Therefore, the sample consists only of those parents who have sought this type of support for themselves and does not include parents who are not aware of these groups or to whom they are not readily available. The sample may also exclude parents who have either dealt with any issues surrounding the loss of their child to schizophrenia or equally, those who refuse the offer of support from carers' groups, opting to support themselves or seek support from within the family. It also does not include a same-sex dyad between parent and child. Inclusion of such parents and dyads may have produced different findings. 
It is acknowledged that the accounts offered by participants may not be isomorphic with the events and experiences of which they speak. The reasons for this may include memory distortions, recall biases and the impact of the context; for example, in one interview, the son who was being discussed was occasionally within earshot of the participant. Despite this, it should not be assumed that autobiographical memory and retrospective accounts are necessarily inaccurate and unstable. There is sufficient research evidence to suggest the contrary and some writers have offered suggestions for improving accuracy, some of which were employed in this study (Blane, 1996; Brewin et al., 1993; Neisser, 1994; Ross \& Conway, 1986; Rubin et al., 1986; Wagenaar, 1986).

Due to the case study approach, the generalisability of this research remains limited. What this study does offer is an in-depth assessment of participants' responses and feelings to enable an exploration as to whether these can be conceptualised in terms of loss and grief. Such close attention to personal accounts is perhaps more important at this early stage of our understanding of parental responses, particularly in light of the specific changes in an adult child with schizophrenia that are experienced by parents. This exploratory study is therefore important to aid our understanding before extending research to a larger sample.

\section{Theoretical implications}

Throughout the interviews, participants preferred to recount their child's behaviours and actions despite being asked direct questions regarding their own feelings. This mind set, alluded to by Miller (1996), limited overt expression of their own emotions. It is possible that this has been brought about by a prolonged period of speaking for their son or daughter and attending to their child's needs whilst suppressing their own. For three of the 
participants, an in-depth, individual exploration of their feelings may have been a unique experience, quite different from what had been provided at NSF groups. The other participant attended family therapy to deal with issues surrounding her son's illness. This may have served to influence her conceptualisation of her son's illness in terms of loss.

When exploring the extent to which parents conceptualised their responses to their child with schizophrenia in terms of loss and grief, it was clear that there were mixed messages. Whilst two participants acknowledged a loss at least to some extent and conceptualised the changes in their child in these terms, another felt that no loss had occurred, as she did not see her son as being any different to how he was before the onset of his illness. The other participant similarly did not conceptualise the changes in his daughter in terms of loss, due mainly to her continued physical presence, yet his further remarks could be interpreted as implying an experience of loss to some extent. The data therefore suggest that there was a difference amongst participants concerning the extent to which responses to their adult child with schizophrenia involved a sense of having lost the child they once knew. Those who did not conceptualise their experiences in terms of loss tended to express methods of coping with the illness itself, whereas those who did acknowledge a loss spoke of coping with this loss and with its associated emotions.

It is possible that there were factors which served to complicate participants conceptualising their experiences as a loss. A delayed diagnosis, as reported by Jean, may have done this as it led to her continuing to cling to aspirations for her son, the relinquishment of which is a major part of the grieving process (Miller, 1996). Another factor, which could in one sense be seen as complicating the portrayal of experiences in terms of loss, is the lack of acceptance of the illness. However, although acceptance of the illness is understood as a 'turning point' in accepting the child as he or she is (Yamashita \& 
Forsyth, 1998), it could be argued in light of critiques of diagnostic categories in mental health (Harper, 1994; Parker et al., 1995) that Amy’s sceptical view of diagnosis should not necessarily be deemed an 'unhealthy' response.

Another factor which may have served to cause differences in participants' conceptualisations of their experiences is their perception of their child's pre-morbid self. Linda alluded to the contrast between pre-morbid behavioural problems and symptoms of schizophrenia in her son. This perceived contrast may have served to aid her in representing her experiences in terms of loss. Amy, on the other hand, had always perceived her son as different to others, and so her perception of the impact of her son's psychotic symptoms on his former self may have been markedly reduced. It could be hypothesised that this may have been a factor in her not conceptualising her experiences as a loss. It could be concluded from this that it is not the existence of 'abnormal' pre-morbid behaviour that complicates representing experiences as loss but rather the parent's perception of the contrast.

As acknowledged by other researchers (Miller, 1996; Parker, 1993; Solomon \& Draine, 1996) it was found that the continued presence of the child served to make the resolution of grief problematic, as explained by Jean. Such continued presence makes it difficult for parents to assimilate the loss, which is said to be an essential part of grief work (Marris, 1986). It would seem that this continued presence also played a role in Graham's initial unwillingness to see his experiences in terms of loss, as for him his daughter's presence meant that in one way he felt that he had not lost her. 
In identifying whether these responses can be accommodated within existing theories of grief, attention should be firstly given to Miller's (1996) adaptation of Worden's (1991) stage approach to grief work. In light of this study, it would seem that Miller's model provides useful tasks to work through 'psychic loss'. It should be noted however that little comment can be made on the latter tasks of this model (the phases that Miller actually adapted) from the data obtained as it would seem that there is little evidence to suggest that the participants were at these stages. Instead, evidence is presented suggesting that the initial task of 'making the loss real' is possibly an important part of the process. Due to the specific nature of this loss the difficulty of proceeding past this stage should not be underestimated, a point to which Miller perhaps paid insufficient attention. Successful completion of this stage may bring a different prognosis of the resolution of grief and possibly the need for a different, less directive approach from the counselling psychologist.

Regarding the utility of applying Stroebe's (1998) model of grief to these issues within therapy, the data suggest that problems may occur. Without an acknowledgement of loss, it could be argued that the parent remains in 'restoration-orientation' without movement to the 'loss-orientation'. If it were deemed necessary to promote 'loss-orientation' (and whether this is always necessary or desirable is open to question), a careful initial focus on conceptualising one's experiences in terms of loss would be required. Following this, the oscillation between the two would need to be carefully monitored throughout therapy.

This study highlights variation in the ways in which parents conceptualise their experiences with their schizophrenic child. Other responses to having an adult child with schizophrenia were also expressed. These included the burden of their child's behaviour, coping with the illness and the type of preferred support. Further research could extend this exploratory 
study by involving a larger sample to increase our understanding of whether responses can be conceptualised in terms of loss and grief. Furthermore, such qualitative data could be examined against quantitative measures collected to assess the conceptualisation of grief.

\section{Implications for the practice of counselling psychology}

If this study has managed to access common parental experiences and conceptualisations to any extent, then counselling psychologists may have a vital role to play in providing a facilitating environment for parents to explore their responses to their children with schizophrenia. The initial stages of therapeutic interventions for such parents could represent opportunities for providing information about mental illness in a supportive environment. Laford (1994) explained that 'when we see mental illness as loss we are at the starting point of the conscious grieving process' (p.11). If this is considered cathartic, then it may be worth spending time exploring whether a conceptualisation in terms of loss is plausible and useful for parents. Tentative challenges by the counselling psychologist concerning how the child is perceived by the parent to be the same and how he or she is perceived as different may make the loss more conscious for the parent. A premature progression to deal with the process of grieving, before ensuring this vital stage is achieved, may cause problems later in therapy.

However, as not all parents in this study felt that they had experienced a loss, the cathartic possibilities of facilitating the construction of parents' feelings in terms of loss may be questionable. In some circumstances, counselling psychologists may not wish to facilitate a construction of loss on the grounds that to do so would overwrite unproblematic parental subjectivities and limit parents' conceptualisations of their experiences. In these cases, counselling psychologists could simply provide a facilitative environment in which parents can express their own feelings and explore their concerns around their child's condition in 
an environment quite different from that which can be offered by health professionals involved in the care of their child.

\section{References}

ATKINSON, S.D. (1994). Grieving and loss in parents with a schizophrenic child. American Journal of Psychiatry, 151, 1137-1139.

BIRCHWOOD, M. \& SMITH, J. (1987). Schizophrenia and the family. In J. ORFORD (Ed.), Coping with disorder in the family (pp. 7-38). London: Croom Helm Ltd. 
BLANE, D.B. (1996). Collecting retrospective data: development of a reliable method and a pilot study of its use. Social Science \& Medicine, 42, 751-757.

BOWLBY, J. (1969). Attachment and loss, volume 1: attachment. London: Hogarth Press.

BOWLBY, J. (1973). Attachment and loss, volume 2: separation: anxiety and anger. London: Hogarth Press.

BOWLBY, J. (1980). Attachment and loss, volume 3: loss: sadness and depression. London: Hogarth Press.

BRAUN, M.J. \& BERG, D.H. (1994). Meaning reconstruction in the experience of parental bereavement. Death Studies, 18, 105-129.

BREWIN, C.R., ANDREWS, B. \& GOTLIB, I.H. (1993). Psychopathology and early experience: a reappraisal of retrospective reports. Psychological Bulletin, 113, 82-98.

CAPLAN, P. (1985). Mother-blaming in major clinical journals. American Journal of Orthopsychiatry, 55, 345-353

CHAFETZ, L. \& BARNES, L. (1989). Issues in psychiatric caregiving. Archives of Psychiatric Nursing, 3, 61-68.

CONRAD, P. (1987). The experience of illness: recent and new directions. Research in the Sociology of Health Care, 6, 1-31. 
COOK, A.S. \& OLTJENBRUNS, K.A. (1989). Dying and grieving: lifespan and family perspectives. New York: Holt, Rhinehart \& Winston.

COOK, J.A., LEFLEY, H.P., PICKETT, S.A. \& COHLER, B.J. (1994). Age and family burden among parents of offspring with severe mental illness. American Journal of Orthopsychiatry, 64, 435-447.

COYLE, A. (1998). Qualitative research in counselling psychology: using the counselling interview as a research instrument. In P. CLARKSON (Ed.), Counselling psychology: integrating theory, research and supervised practice (pp. 56-73). London: Routledge.

CROTTY, P. \& KRULYS, R. (1986). Are schizophrenics a burden to their families? Significant others’ views. Health and Social Work, 11, 173-188.

DAVIS, D.J. \& SCHULTZ, C.L. (1998). Grief, parenting, and schizophrenia. Social Science \& Medicine, 46, 369-379.

DAVY, J. (1998). Constructionist approaches to bereavement and therapy: part 1 . Counselling Psychology Review, 13, 7-15.

DOKA, K.J. \& MARTIN, T. (1998). Masculine responses to loss: clinical implications. Journal of Family Studies, 4, 143-158.

DOLL, W. (1976). Family coping with the mentally ill: an unanticipated problem of deinstitutionalization. Hospital and Community Psychiatry, 27, 182-185. 
FORREST, G.C. (1983). Mourning perinatal death. In J.A. DAVIS, M.P.P. RICHARDS \& N.R.C. ROBERTSON (Eds), Parent-baby attachment in premature infants (pp. 200210). London: Croom Helm Ltd.

FREUD, S. (1917). Mourning and melancholia. Standard edition (vol. XIV). London: Hogarth Press, 1957.

GIBBONS, J.S., HORN, S.H., POWELL, J.M. \& GIBBONS, J.L. (1984). Schizophrenic patients and their families: a survey in a psychiatric service based on a DGH unit. British Journal of Psychiatry, 144, 70-77.

GLICK, I.D., WEISS, R.S. \& PARKES, C.M. (1974). The first year of bereavement. New York: John Wiley.

GUBMAN, G. \& TESSLER, R. (1987). The impact of mental illness on families. Journal of Family Issues, 8, 226-245.

HARPER, D.J. (1994). The professional construction of 'paranoia' and the discursive use of diagnostic criteria. British Journal of Medical Psychology, 67, 131-143.

HATFIELD, A.B. (1978). Psychological costs of schizophrenia to the family. Social Work, 23, 355-359. 
HATFIELD, A.B. (1987). Coping and adaptation: a conceptual framework for understanding families. In A.B. HATFIELD \& H.P. LEFLEY (Eds), Families of the mentally ill: coping and adaptation (pp. 60-84). New York: Guilford Press.

HOENIG, J. \& HAMILTON, M.W. (1966). The schizophrenic patient in the community and his effect on the household. International Journal of Social Psychiatry, 12, 165-176.

HORWITZ, A. \& REINHARD, S.C. (1995). Ethnic differences in caregiving duties and burdens among parents and siblings of persons with severe mental illness. Journal of Health and Social Behavior, 36, 138-150.

JONES, E.E. (1993). Special section: single case research in psychotherapy. Journal of Consulting and Clinical Psychology, 61, 371-430.

JOSSELSON, R. \& LIEBLICH, A. (1993). The narrative study of lives. Hewbury Park, CA: Sage.

KOHNER, N. \& HENLEY, A. (1992). When a baby dies: the experience of late miscarriage, stillbirth and neonatal death. London: Pandora Press.

LAFORD, V. (1994). Grieving in mental illness: a guide for patients and their caregivers. University of Toronto Press.

LINDEMANN, E. (1944). Symptomatology and management of acute grief. American Journal of Psychiatry, 101, 141-148. 
LINDEMANN, E. (1979). Beyond grief: studies in crisis intervention. New York: Aronson.

LITTLEWOOD, J.L., CRAMER, D., HOESKSTRA-WEEBERS, J.E.W.M. \& HUMPHREY, G.B. (1991). Gender differences in parental coping following their child's death. British Journal of Guidance and Counselling, 19, 139-148.

LONG, J. (1992). Grief and loss in childbirth. Midwives Chronicle, 105, 51-54.

MACCARTHY, B. (1988). The role of relatives. In A. LAVENDER \& F.HOLLOWAY (Eds), Community care in practice (pp. 207-227). Chichester: John Wiley.

MACGREGOR, P. (1994). Grief: the unrecognised parental response to mental illness in a child. Social Work, 39, 160-166.

MANDER, R. (1994). Loss and bereavement in childbearing. London: Blackwell Scientific Publications.

MARRIS, P. (1986). Loss and change. London: Routledge.

MARTIN, T. \& DOKA, K.J. (1996). Masculine grief. In K.J. DOKA (Ed.), Living with grief after sudden loss: suicide, homicide, accident, heart attack, stroke (pp.161-171). Washington, DC: Taylor \& Francis. 
MAURIN, J.B. \& BOYD, C.B. (1990). Burden of mental illness on the family: a critical review. Archives of Psychiatric Nursing, 4, 99-107.

McADAMS, D. (1988). Biography and life narratives. Journal of Personality, 56, 1-18.

McELROY, E. (1987). The beat of a different drummer. In A.B. HATFIELD \& H.P. LEFLEY (Eds), Families of the mentally ill: coping and adaptation (pp. 225-243). New York: Guilford Press.

MILLER, F. (1996). Grief therapy for relatives of persons with serious mental illness. Psychiatric Services, 47, 633-637.

MILLER, F., DWORKIN, J., WARD, M. \& BARONE, D. (1990). A preliminary study of unresolved grief in families of seriously mentally ill Patients. Hospital and Community Psychiatry, 41, 1321-1325.

NEISSER, U. (1994). Self narratives: true and false. In U. NEISSER \& R. FIVUSH (Eds), The remembering self: construction and accuracy in the self-narrative (pp. 1-18). New York: Cambridge University Press.

OLSHANSKY, S. (1962). Chronic sorrow: a response to having a mentally defective child. Social Casework, 43, 191-193.

PARIANTE, C.M. \& CARPINIELLO, B. (1996). Family burden in relatives of schizophrenics and of people with mental retardation: a comparative study. European Psychiatry, 11, 381-385. 
PARKER, B.A. (1993). Living with mental illness: the family as caregiver. Journal of Psychosocial Nursing, 31, 19-21.

PARKER, I, GEORGACA, E., HARPER, D, McLAUGHLIN, T. \& STOWELL-SMITH, M. (1995). Deconstructing psychopathology. London: Sage.

PARKES, C.M. (1965). Bereavement and mental illness. British Medical Journal, 38, 126.

PARKES, C.M. (1980). Bereavement counselling: does it work? British Medical Journal, 281, 3-10.

PARKES, C.M. (1985). Bereavement. British Journal of Psychiatry, 146, 11-17.

PARKES, C.M. (1993). Bereavement as a psychosocial transition. In M. STROEBE, W. STROEBE \& R.O. HANSSON (Eds), Handbook of bereavement (pp.91-101). New York: Basic Books.

PARKES, C.M. (1998). Bereavement: studies of grief in adult life ( $3^{\text {rd }}$ ed.). Madison, CT: International University Press.

POTASZNIK, H. \& NELSON, G. (1984). Stress and social support: the burden experienced by the family of a mentally ill person. American Journal of Community Psychology, 12, 589-607. 
RANDO, T.A. (1986). Individual and couples treatment following the death of a child. In T.A. RANDO (Ed.), Parental loss of a child (pp. 82-104). Champaign, IL: Research Press.

RAPHAEL, B. \& NUNN, K. (1988). Counselling the bereaved. Journal of Social Issues, 3, 191-206.

ROSS, M. \& CONWAY, M. (1986). Remembering one's own past: the construction of personal histories. In R.M. SORRENTINO \& E.T. HIGGINS (Eds), Handbook of motivation and cognition: foundations of social behavior (pp. 122-144). New York: John Wiley.

RUBIN, D.C., WETZLER, S.E. \& NEBES, R.D. (1986). Autobiographical memory across the lifespan. In D.C. RUBIN (Ed.), Autobiographical memory (pp. 202-221). Cambridge: Cambridge University Press.

RUNYAN, W.M. (1982). Life histories and psychobiography: explorations in theory and method. New York: Oxford University Press.

RYAN, K. (1993). Mothers of adult children with schizophrenia: an ethnographic study. Schizophrenia Research, 11, 21-31.

SCHATZ, W.H. (1986). The grief of fathers. In T.A. RANDO (Ed.), Parental loss of a child (pp. 134-162). Champaign, IL: Research Press. 
SCHUT, H., STROEBE, M., DE KEIJSER, J. \& VAN DEN BOUT, J. (1997). Intervention for the bereaved: gender differences in the efficacy of two counselling programmes. British Journal of Clinical Psychology, 36, 63-72.

SMITH, J.A. (1990). Transforming identities: a repertory grid case-study of the transition to motherhood. British Journal of Medical Psychology, 63, 239-253.

SMITH, J.A. (1991). Conceiving selves: a case-study of changing identities during the transition to motherhood. Journal of Language and Social Psychology, 10, 225-243.

SMITH, J.A. (1996). Beyond the divide between cognition and discourse: using interpretative phenomenological analysis in health psychology. Psychology and Health, $11,261-271$.

SMITH, J.A., FLOWERS, P. \& OSBORN, M. (1997). Interpretative phenomenological analysis and the psychology of health and illness. In L.YARDLEY (Ed.), Material discourses of health and illness (pp. 68-91). London: Routledge.

SMITH, J.A., HARRE, R. \& VAN LANGENHOVE, L. (1995). Idiography and the casestudy. In J.A. SMITH, R. HARRE \& L. VAN LANGENHOVE (Eds), Rethinking psychology (pp. 59-69). London: Sage.

SMITH, J.A., JARMAN, M. \& OSBORN, M. (1999). Doing interpretative phenomenological analysis. In M. MURRAY \& K. CHAMBERLAIN (Eds), Qualitative health psychology: theories \& methods (pp. 218-240). London: Sage. 
SOLOMON, P. \& DRAINE, J. (1996). Examination of grief among family members of individuals with serious and persistent mental illness. Psychiatric Quarterly, 67, 221-234.

STROEBE, M. (1992). Coping with bereavement: a review of the grief work hypothesis. Omega, 26, 19-42.

STROEBE, M. (1994). The broken heart phenomenon: an examination of the mortality of bereavement. Journal of Community and Applied Social Psychology, 4, 47-61.

STROEBE, M. (1998). New directions in bereavement research: exploration of gender differences. Palliative Medicine, 12, 5-12.

STROEBE, M., VAN DEN BOUT, J. \& SCHUT, H. (1994). Myths and misconceptions about bereavement: the opening of a debate. Omega, 29, 187-203.

TERKELSEN, K.G. (1987). The evolution of families' responses to mental illness through time. In A.B. HATFIELD \& H.P. LEFLEY (Eds), Families of the mentally ill: coping and adaptation (pp. 151-166). New York: Guilford Press.

THOMPSON, E. \& DOLL, W. (1982). The burden of families coping with the mental illness: an ideal type. Psychosocial Rehabilitation Journal, 10, 3-6.

WAGENAAR, W.A. (1986). My memory: a study of autobiographical memory over six years. Cognitive Psychology, 18, 225-252. 
WORDEN, J.W. (1991). Grief counselling and grief therapy: a handbook for the mental health practitioner. London: Routledge.

WORDEN, J.W. (1996). Children and grief: when a parent dies. New York: Guilford Press.

YAMASHITA, M. \& FORSYTH, D.M. (1998). Family coping with mental illness: an aggregate from two studies, Canada and United States. Journal of the American Psychiatric Nurses Association, 4, 1-8. 